\title{
A NEW ASSESSMENT OF RELAP5-3D USING A GENERAL ELECTRIC LEVEL SWELL PROBLEM
}

D. L. Aumiller, E. T. Tomlinson, and W. G. Clarke

USDOE Contract No. DE-AC11-98PN38206

\section{NOTICE}

This report was prepared as an account of work sponsored by the United States Government. Neither the United States, nor the United States Department of Energy, nor any of their employees, nor any of their contractors, subcontractors, or their employees, makes any warranty, express or implied, or assumes any legal liability or responsibility for the accuracy, completeness or usefulness of any information, apparatus, product or process disclosed, or represents that its use would not infringe privately owned rights. 


\section{DISCLAIMER}

This report was prepared as an account of work sponsored by an agency of the United States Government. Neither the United States Government nor any agency thereof, nor any of their employees, make any warranty, express or implied, or assumes any legal liability or responsibility for the accuracy, completeness, or usefulness of any information, apparatus, product, or process disclosed, or represents that its use would not infringe privately owned rights. Reference herein to any specific commercial product, process, or service by trade name, trademark, manufacturer, or otherwise does not necessarily constitute or imply its endorsement, recommendation, or favoring by the United States Government or any agency thereof. The views and opinions of authors expressed herein do not necessarily state or reflect those of the United States Government or any agency thereof. 


\section{DISCLAIMER}

Portions of this document may be illegible in electronic image products. Images are produced from the best available original document. 


\title{
A NEW ASSESSMENT OF RELAP5-3D USING A GENERAL ELECTRIC LEVEL SWELL PROBLEM
}

\author{
D.L. Aumiller \\ E.T. Tomlinson \\ W.G. Clarke \\ Bechtel Bettis, Inc. \\ Bettis Atomic Power Laboratory \\ P.O. Box 79 \\ West Mifflin, PA 15122-0079
}

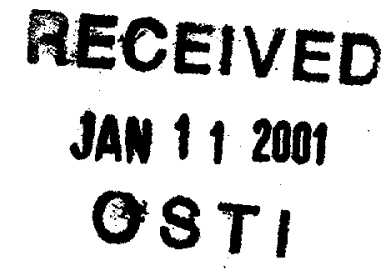

\begin{abstract}
The RELAP5-3D (version bt) computer program was used to assess a GE level swell experiment. The primary goal of the new assessment models was to faithfully represent the experimental facility and instrumentation. In developing the new models, a non-physical representation of the vessel heads in a previous assessment was found. This distortion resulted in predictions that closely matched the experimental data, but were in error. The new assessment also highlighted an instability in the calculation of interfacial drag. To explore this issue, analyses were performed using three different interfacial drag correlations appropriate for large diameter pipes and/or vessels. The results of this study show that the Kataoka-Ishii correlation, which is currently used in RELAP5-3D, compares most favorably with the experimental data. Additionally, a numerical instability was uncovered with the analysis performed using the Gardner correlation and was traced to the calculation of bubble diameter in the bubbly flow regime.
\end{abstract}

\section{Introduction}

Many of the transients of interest to the thermalhydraulic safety community (Loss of Coolant Accidents and Steam Line Ruptures) are characterized by fast depressurization due to the loss of liquid inventory. This depressurization causes flashing of the liquid as the pressure falls below the saturation pressure for the fluid temperature. This flashing results in the formation of bubbles which increase the volume of the mixture and produces a level swell in the presence of a free surface. Accurate prediction of the flashing rate and void distribution are therefore important for thermal-hydraulic safety programs.

Circa 1980, General Electric performed a series of experiments [1] to measure both void distribution and level swell phenomena for depressurization transients. These tests have become standard qualification problems for reactor safety programs.
Previous versions of the RELAP5 program have been assessed relative to GE Level Swell tests [2]. These assessments have been updated in this paper. The result is a model which faithfully represents the full test facility and provides improved accuracy relative to the experimental data.

\section{Description of the Test}

The GE Level Swell experiments were designed to measure transient void fraction profiles in a large tank which was depressurized via a blowdown line and orifice. Two different vessels sizes (1 and $4 \mathrm{ft}$ nominal diameter) were used in the experimental program. This paper will focus on test number 1004-3 performed with the smaller of the two vessels.

A schematic of the experimental facility for the small vessel blowdown tests is shown in Figure 1. The experimental vessel was constructed from a 
length of 12 inch, schedule 80 pipe. The volume of the vessel is $0.28 \mathrm{~m}^{3}\left(10.0 \mathrm{ft}^{3}\right)$. In an attempt to prevent liquid from being entrained out of the test, the blowdown pipe was connected near the top of the vessel. The depressurization rate was controlled via an orifice in the blowdown line. For the test being considered, the diameter of the blowdown orifice was $0.00952 \mathrm{~m}$ (0.375 in). A perforated plate could be inserted in the vessel to examine the effect of a hydraulic resistance on the experiments; however, this plate was not installed for test number 1004-3.

The instrumentation of the test included one absolute and six differential pressure gauges and several temperatures detectors. As shown in Figure 1, the regions between adjacent pressure taps are referred to as Levels (or segments) and are numbered sequentially starting at the bottom. The differential pressure measurements were used to infer the void fraction in each segment by assuming that hydrostatic head was the only component contributing to the pressure difference. The height of the two-phase level was determined using a two-step process. First, the segment containing the two-phase level was heuristically determined using the axial void profile in the vessel. Next the position of the two-phase level in that segment was calculated assuming the void fraction below the two-phase level was equal to the void fraction in the segment directly beneath it.

The initial conditions for test number 1004-3 were a system pressure of $6.92 \mathrm{MPa}(1011 \mathrm{psia})$ and a water level of $3.167 \mathrm{~m}(10.4 \mathrm{ft})$. Since the experimental fluid temperatures were not included in the test report, the initial liquid temperature was assumed to correspond to the saturation temperature, $559 \mathrm{~K}\left(546^{\circ} \mathrm{F}\right)$.

\section{Original Assessment Model}

The input description for the original assessment was obtained from the RELAP5-3D program developers, Idaho National Engineering and Environmental Laboratory (INEEL). In this model, the vessel is represented using 27 volumes. The 23 volumes which represent the cylindrical portion of the tank are each $0.1524 \mathrm{~m}(0.5 \mathrm{ft})$ in length and have a flow area of $0.0729 \mathrm{~m}^{2}$ $\left(0.785 \mathrm{ft}^{2}\right)$. This flow area corresponds to a inside tank diameter of $0.3048 \mathrm{~m}(1 \mathrm{ft})$. Both the top and bottom head are modelled using two volumes each. Neither the level tracking nor the vertical stratification options were used in the original assessment. The volume weighted void fraction for the volumes in each segment are compared with the experimentally determined segment void fractions. Furthermore, the heat capacity of the vessel wall is omitted in this model.

In the original assessment, the blowdown line in the experiment was not explicitly modelled. The blowdown orifice was assumed to be located at the top of the vessel and oriented vertically; however, in the experimental facility the blowdown line exits through the side of the tank near the top, and there is a short length of pipe between the vessel wall and the orifice.

\section{Revised Assessment Model}

In a previous of assessment of RELAP5 [3], it was concluded that faithful representations of the experimental facility including instrumentation, the boundary conditions and the initial conditions were required to obtain an undistorted assessment. This philosophy was used in the creation of the revised assessment model.

The flow area of the cylindrical portion of the vessel was modified to be consistent with a 12 inch nominal, schedule 80 pipe. This change in geometry represents a reduction in flow area of over $10 \%$ relative to the original model. The revised model uses 25 cylindrical volumes and uses only one volume to represent each head. Furthermore, the fluid volume associated with the vessel heads was significantly modified from the value used in the original assessment. Based on the scaled drawings in Reference 1, the vessel heads were assumed to be hemispherical; fluid volumes were calculated consistent with this assumption. The fluid mass of the bottom two volumes is approximately $50 \%$ larger in the revised model than in the original assessment model. The value used in the original assessment is incompatible with any likely geometry which could have been used in the test and is viewed to be in error. Differences in modelling the vessel heads 
were shown to have a significant effect on the transient evolution. This effect is discussed in the following section.

Additionally, the new assessment model explicitly represents both the blowdown line and the orifice. Consistent with the test, the discharge line was modelled as 2 inch schedule 80 pipe. Unlike the original assessment model, a length of pipe was located between the vessel wall and the orifice. The length of this pipe was determined to be $0.0508 \mathrm{~m}(0.167 \mathrm{ft})$ from the vessel using the scaled drawing provided in reference [1]. This feature was considered to be important to model accurately the pressure losses associated with the contraction in the nozzle and the orifice. For most of the transient, choked flow occurs at the orifice. The RELAP5 critical flow model ignores form losses at a location once choking occurs. Therefore, in the original assessment model the contraction pressure drop associated with the nozzle is largely ignored since choked flow occurs at this location; however, the revised model includes this effect.

The junction representing the blowdown orifice was modelled using the abrupt area change model. The discharge coefficients for the default RansomTrapp critical flow model for subcooled, two-phase and superheated conditions were assumed to be $1.0,0.65$ and 0.65 , respectively. These values were consistent with the original RELAP5 assessment of this problem. The vertical section of the blowdown line was modelled using 5 volumes and was assumed to be approximately $5 \mathrm{~m}(16.5 \mathrm{ft})$ in length. Since conditions downstream of the critical flow location do not affect the flow rate, accurate modelling of the blowdown line is not required for this assessment.

Early analyses performed with this revised model showed a propensity to depressurize too rapidly. One possible explanation for this behavior is the omission of the wall heat capacity. In the experiment, the wall could transmit heat to the liquid as the liquid temperature decreases with the saturation temperature. This heat transfer would tend to increase the pressure in the vessel. To assess the effect of wall heat capacity, analyses were performed with and without heat structures.
The initial vessel wall temperature was assumed to be the saturation temperature, $559 \mathrm{~K}\left(546^{\circ} \mathrm{F}\right)$.

To be consistent with the experiment, this assessment infers the average segment void fractions using the differential pressures. To establish the correct initial hydrostatic head required to infer the initial void fractions, a 10 second null transient was run prior to initiating the blowdown. For this problem, the differences between the inferred void fraction using the experimental algorithm and the volume averaged void fraction in the segment were small.

Unlike the original assessment, the current assessment used the level tracking option for the volumes representing the vessel. The level tracking model was used with the RELAP5-3D control variables to calculate the height of the twophase level in the vessel. The control system examined the variable vollev, the height of the level in a volume, for each volume. If the vollev variable was non-zero for a given volume, an appropriate two-phase level was computed based on the value of vollev and on the location of that volume within the vessel.

Finally, no developmental (Card 1) options were used in these analyses except as described in the interfacial drag sensitivity studies.

\section{Comparison of Model Results}

The transient pressure measurement is judged to have the least uncertainty of all of the measured or inferred experimental parameters; however, no experimental uncertainty for this variable was provided with the data. Figure 2 presents the predicted pressure responses of the revised models (i.e. with and without heat capacity effects) and the original model compared with the experimental data. As expected, the modelling of the wall heat capacity results in a slower depressurization.

Figures 3-5 are comparisons of the experimental and predicted void fractions in the first, second and fourth segments, or levels, for the original and two revised assessment models. With the exception of Level 6, all of the void fraction curves are characterized by an initial increase in void fraction, 
followed a region of quasi-equilibrium void fraction. For Levels 4 and 5 following the quasiequilibrium phase, the void fraction monotonically increases as the level falls through the segment.

A cursory examination of the Level 1 void fraction predictions, Figure 3, indicates that while all of the predictions fall within experimental uncertainty, the original model predictions lie closer to the experimental data. However, this enhanced accuracy is directly related to the non-physical modelling of the bottom vessel head. As discussed above, the revised models have $50 \%$ more fluid mass in the bottom two volumes; therefore, as the pressure decreases and the fluid flashes more steam is generated in the revised model. The inset in Figure 3 shows the rate at which steam leaves the bottom most volume. This shows that more steam is produced in the revised model thus increasing the void fraction in the first level. The heat capacity effects are negligible for these predictions.

Figure 4 shows that the void fraction predictions for Level 2 are similar for all three models. The prediction of the new model without the heat capacity effect shows high frequency oscillations, otherwise, the heat capacity effects are negligible. As in Level 1, all of the predictions fall within the experimental uncertainty.

The predictions of the Level 4 void fraction, shown in Figure 5, exhibit several interesting features. First, the inclusion of the wall heat capacity improves the predictions in Level 4 relative to data. Based on this comparison, wall heat capacity is deemed to be an important phenomenon in this experiment. Furthermore, the revised models provide a much better calculation than the original model. Although all of the models calculate the correct quasi-equilibrium void fraction, the revised models better match the rate at which the twophase level falls through Level 4 as determined by the slope of the void fraction curve later in the transient.

The new models, especially the model without wall heat capacity, are characterized by high frequency oscillations. Based on previous assessments of the RELAP5-3D critical flow model [3], the critical flow model was first suspected to be the cause of the high-frequency oscillations. However, as seen in Figure 6, no oscillations were observed in the predicted critical flow during the period when void fraction oscillation were observed. Therefore, other sources of numerical oscillations were investigated.

\section{Timestep Sensitivity}

One of the notable differences between the old and revised assessment analyses was a large difference in time step size. It is known that in certain circumstances, the results of thermal-hydraulic safety codes can be sensitive to timestep size. The original assessment used a 200 msec timestep for most of the transient. The revised models were Courant limited in the blowdown line downstream of the orifice. The resulting timestep size, which increased as the flow in the blowdown decreased, was between 1.5 and $50 \mathrm{msec}$.

To determine the effect of timestep on the analysis, the original assessment was rerun using a constant 2 msec timestep. Figure 7 shows the results of this calculation compared with the original calculation for the Level 3 void fraction. This figure shows the same high frequency oscillations as seen in the revised models.

Further investigation revealed the source of this numerical oscillation to be an oscillation in interfacial drag $(f i j)$. The inset in Figure 7 , shows this parameter for both timestep sizes for a location in Level 3. The interfacial drag oscillations were traced to non-physical oscillations between the bubbly and slug flow regimes.

For two-phase flow, flow regime and interfacial drag are interdependent since the void fraction determines the flow regime and void fraction is dependent on interfacial drag which in turn depends on flow regime. To determine whether these oscillations were unique to the default interfacial drag model, sensitivity studies were performed and are described in the next section.

\section{Interfacial Drag Study}

For large pipes or vessels (D>0.08 m), RELAP5-3D uses the Kataoka-Ishii [4] drift flux 
model to determine the drag between the twophases. One feature of this model is that the drift flux velocity, which is used to determine the interfacial drag, depends on flow regime. This explains why the flow regime oscillations led to interfacial drag, and ultimately void fraction, oscillations as discussed in the previous section. To investigate the effect of interfacial drag on these high frequency oscillations, other interfacial correlations were examined.

The RELAP5-3D program has available as a developmental option (Card 1 option 82) the ability to use the Gardner drift flux correlation [5] for very large pipes or vessels $(\mathrm{D}>0.24 \mathrm{~m})$. To activate Gardner correlation, Card 1 option 78, which affects the formulation of the drift flux distribution parameter, must also be used. While the Gardner correlation is independent of flow regime, the RELAP5-3D implementation is dependent on mass flux. This correlation is only used for low mass flux situations. For high mass flux situations the Kataoka-Ishii correlation is used.

In addition to the Gardner correlation, the VeaLahey correlation [6] was implemented in RELAP5-3D for this study. Like the Gardner correlation, this correlation is also flow regime independent and applicable to large pipes or vessels (D>0.2 $\mathrm{m}$ ); however, unlike the implementation of Gardner correlation, the implementation of the Vea-Lahey correlation is independent of mass flux. Similar to the implementation of the Gardner correlation, Card 1 option 78 is required for the use of this interfacial drag correlation.

To determine the effect of the interfacial drag on the transient evolution, all three options were exercised. This sensitivity study was performed using the revised model which included the wall heat capacity effects.

Figures 8-13 present comparisons of the predicted void fractions and the experimental data for Levels $1-6$, respectively. Note that there are two curves for the Gardner correlation, with and without modification of the bubbly and slug flow regime interfacial heat transfer coefficients (Card 1 option 61). This sensitivity is discussed later in this section.

Based on Figures 8-13, the following conclusions can be made:

- Kataoka-Ishii over-predicts the void fraction at the lower elevations (Levels 1-3) which are characterized by the lowest void fractions, but predicts the quasi-equilibrium void fractions well at higher elevations in the test vessel.

- Gardner tends to under-predict the quasiequilibrium void fraction at all elevations, except Level 6.

- Vea-Lahey predicts the quasi-equilibrium void fractions the best for Levels 1 and 2, but exhibits the incorrect trend of increasing void fractions during the equilibrium phase.

As seen in Figures 4 and 5, the inclusion of the wall heat capacity resulted in a more stable solution during the time for which experimental data are available; however, oscillations are noted at later periods in the transient. Figure 14 provides a comparison of the predicted Level 2 void fraction for the different interfacial drag correlations for the entire 400 seconds of the transient. This figure shows that the calculation which uses the KataokaIshii correlation becomes unstable. This oscillation was also traced back to an oscillation in predicted flow regime. Specifically, the calculated drift velocity in the drift flux model oscillated based on flow regime; however, the distribution parameter, $\mathrm{C}_{0}$, did not oscillate.

The calculation which used the Gardner correlation is characterized by two separate periods of oscillation. An investigation of the low frequency oscillations, which occur early in the transient, identified oscillations in the fluid side interfacial heat transfer (hif) as a potential source of the oscillations. To examine this effect, a developmental option that modifies the bubbly and slug flow interfacial heat transfer coefficients (Card 1 option 61) was examined. Further investigation showed that the oscillation was due to the correlation used to determine bubble size. The default bubble size model uses a Weber number criterion, whereas, Card 1 option 61 uses a Laplace number formulation, which is independent of 
relative velocity. As shown in Figures $8-12$, this option removes the oscillations while not affecting the overall results. The high frequency oscillations late in the transient are caused by oscillations in the critical flow model. This behavior was also seen in another assessment of the RELAP5-3D [3].

Finally, the Vea-Lahey model showed no high frequency oscillations. This trend is to be expected since the magnitude of the oscillation reflects the degree to which the interfacial drag correlation depends on the calculated local conditions. Using this criterion, the Kataoka-Ishii model would be expected to oscillate the most and the Vea-Lahey model the least. The results shown in Figure 14 are consistent with this trend.

Another measured parameter of interest is the lheight of the two-phase level in the vessel. Figure 15 is a comparison of the predicted height of the two-phase level for the different interfacial drag correlations with the experimental data. This figure indicates that the level calculations using each of the drag correlations are always within the experimental uncertainty. Furthermore, this figure shows that all three of the predictions have the same shape but are offset in time. This same phenomena can be seen in the void fraction predictions for Level 4 and 5 as shown in Figures 11 and 12. These trends are also consistent with the pressure response (not shown) in that the predictions for the Gardner correlation, precede the predictions for the Kataoka-Ishii correlation which in turn precede the Vea-Lahey correlation.

In determining the cause for the apparent lag among the interfacial drag correlations, the pressure response was examined first since it was believed to be the cause of the level and void fraction differences. It was assumed that there would be an inverse relationship between depressurization rate and mass flow at the orifice, shown in Figure 16. Using this logic, the orifice flow associated with the Gardner correlation should be the highest since it depressurized the fastest. However, Figure 16 shows the opposite behavior. This effect is most pronounced early in the transient, shown in the Figure 16 inset.
The experiment was designed to allow only vapor to leave the vessel. The critical flow behavior for pure steam should behave like the long term response $(t>25 \mathrm{sec})$ in Figure 16, where the flow rate is characterized by a smooth reduction as the driving pressure (and hence density) of the steam decrease. Based on this assumption, the short duration flow increases early in the transient are problematic. These early flow increases were traced to a two-phase mixture leaving the vessel during that portion of the transient. The inset of Figure 17 provides a plot of the liquid fraction at the blowdown orifice for each of the interfacial drag correlations. This figure shows that the increases in critical mass flow are directly related to changes in the two-phase density exiting the vessel; however, this still does not explain why the interfacial drag correlation which yields the largest mass flow at the orifice also yields the lowest depressurization rate.

The explanation of the apparent inconsistency between the mass flow and pressure predictions is related to the interplay of the two-phase conditions at the blowdown orifice and the critical velocity. Figure 17 presents a plot of the predicted sonic velocity at the orifice. This figure, when compared with the inset, shows that the presence of a small amount liquid at the orifice significantly reduces the sonic velocity.

The presence of the liquid at the orifice has two competing effects on the mass flow through the orifice. The first effect is to decrease sonic velocity which tends to decrease mass flow. The second effect is to increase the mixture density which is convected through the orifice. This effect tends to increase the mass flow. For the conditions of this test, the density effect dominates and the presence of the liquid causes the mass flow increase seen is Figure 16.

Based on this information, the cause and effect relationship between the interfacial drag and the timing of the different phenomena can be established; the Gardner correlation causes less liquid to be carried to the orifice, this leads to a smaller decrement in vapor velocity. Since it is the volumetric flow, and not the mass flow, which 
determines the depressurization rate, the case with the least carryover (Gardner) depressurizes first.

\section{Conclusions}

The GE Level Swell, test number 1004-3, was used to perform an assessment of the RELAP5-3D program. Three different input models, the original model and two revised models, were used in this assessment. The results indicated that the heat capacity of the walls was very important in the calculation of the rate at which the two-phase level falls.

When comparing the results of the original and revised assessments models, a significant difference in Level 1 void fractions was noted. This was caused by a non-physical model of the vessel heads. The effect of this distortion was to erroneously provide results which were in better agreement with the data than warranted. This effect reinforces the need to model both the experimental facility and instrumentation accurately to obtain an honest assessment of the computer program.

When Level 1 is not considered, the overall results of the revised assessment model are better than those obtained with the original assessment model compared to the experimental data.

Another interesting feature of this assessment is the prediction of a two-phase mixture at the orifice. This was an unexpected effect and the amount of liquid present at the orifice significantly influenced the transient evolution.

Comparing the results of the different interfacial drag correlations, the accuracy of the quasiequilibrium void fraction predictions were judged to be most important. The timing associated with the level decrease is related to liquid carryover at the orifice which is affected by other items in addition to the bubbly and slug flow drag. The most important of these other phenomena is the interfacial drag on the drops in the vapor space in the vessel. Therefore, it did not seem appropriate to judge the bubbly and slug flow correlations based on parameters for which other phenomena are highly important. Using this criterion the
Kataoka-Ishii correlation is judged to the best; however, the predictions of the quasi-equilibrium void fractions fall within the experimental uncertainty for all of the correlations. The Kataoka-Ishii interfacial drag correlation was shown to oscillate due to flow regime oscillations. This behavior shows the need for additional work in smoothing the behavior of the interfacial drag between the bubbly and slug flow regimes.

Overall, RELAP5-3D performed well for all of the transient blowdown analyses in this study. Specifically, the level tracking model was exercised and performed well. Although not explicitly shown, instabilities, similar to those discussed in Reference [3], were found in the default critical flow model late in the transient. These oscillations had no discernible effect on the parameters for which experimental data existed.

\section{References}

1. Findlay, J.A. and G.L. Sozzi, "BWR RefillReflood Program - Model Qualification Task Plan," NUREG/CR-1899, 1981.

2. Carlson, K.E. et al., "RELAP5/MOD3 Code Manual Volume III: Developmental Assessment Problems," NUREG/CR-5535, EGG-2596, (Draft), June 1990.

3. Tomlinson, E.T. and D.L. Aumiller, "An Assessment of RELAP5-3D Using the Edwards-O'Brien Blowdown Problem," Presented at 1999 RELAP5 International Users Seminar, Park City, Utah, available as B-T3271 from DOE Office of Scientific and Technical Information, 1999.

4. Kataoka, I. and M. Ishii, "Drift Flux Model for Large Diameter Pipe and New Correlation of Pool Void Fraction," International Journal of Heat and Mass Transfer, 30, pp 1927-1939, 1987.

5. Gardner, G., "Fractional Vapour Content of a Liquid Pool Through which Vapour is Bubbled," International Journal of Multiphase Flow, 6, pp 399-410, 1980.

6. Vea, H.W. and R.T. Lahey, Jr., "An Exact Analytical Solution of Pool Swell Dynamics During Depressurization by the Method of Characteristics," Nuclear Engineering and Design, 45, pp 101-116, 1978. 


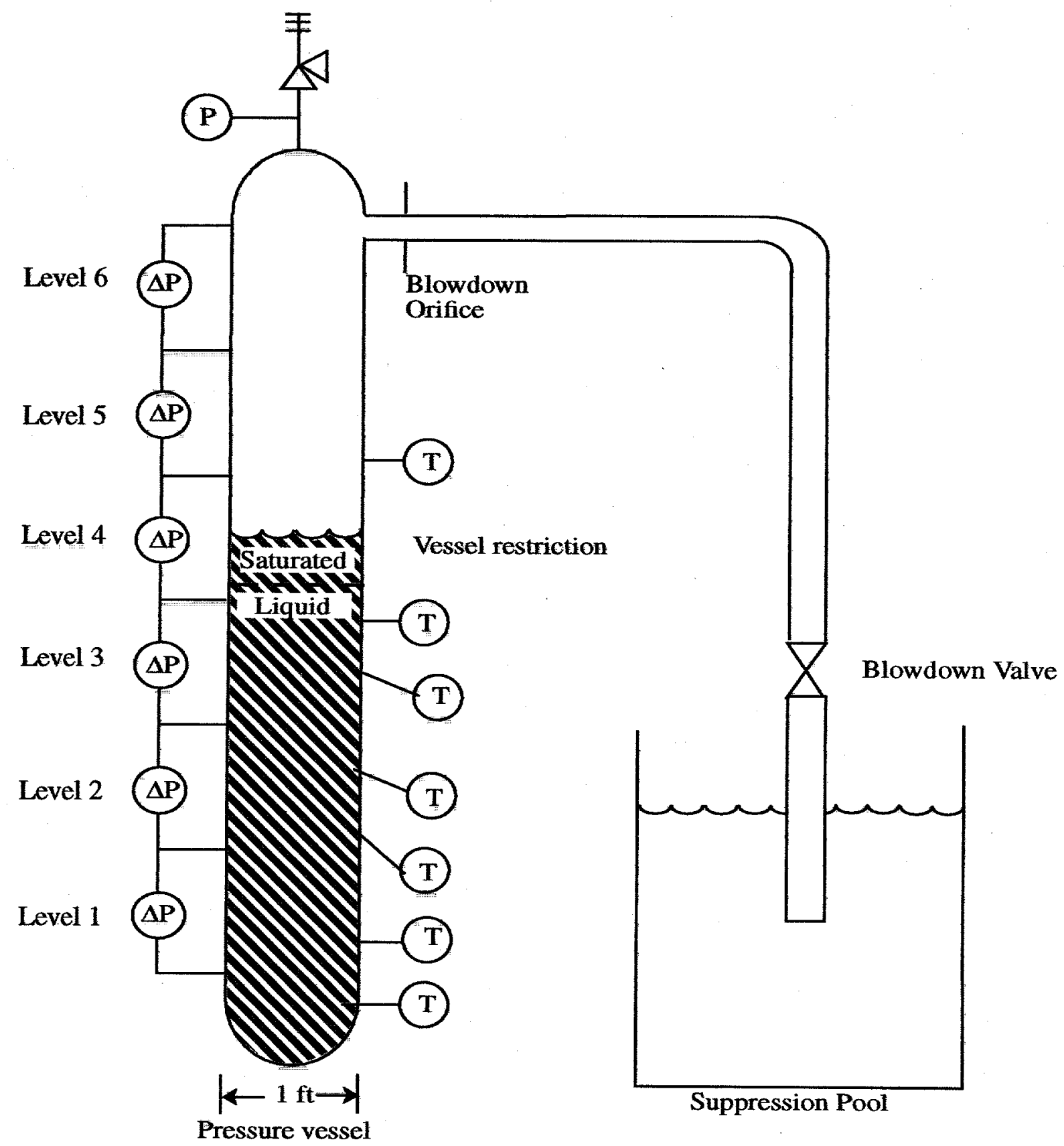

Figure 1: Schematic of the Small Vessel GE Level Swell Facility 
September 12-14, 2000

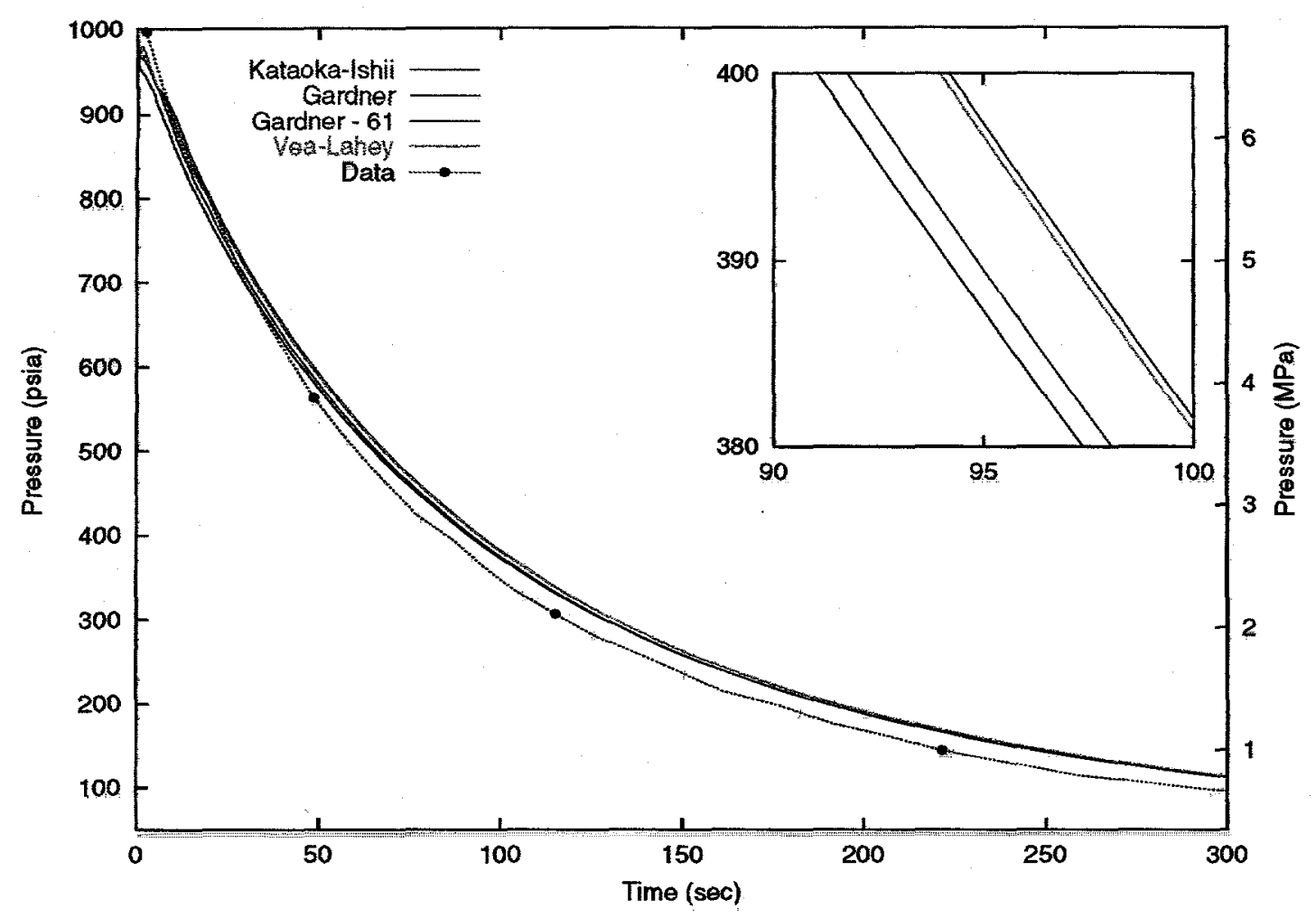

Figure 2: The Effect of Wall Heat Capacity on Pressure Response

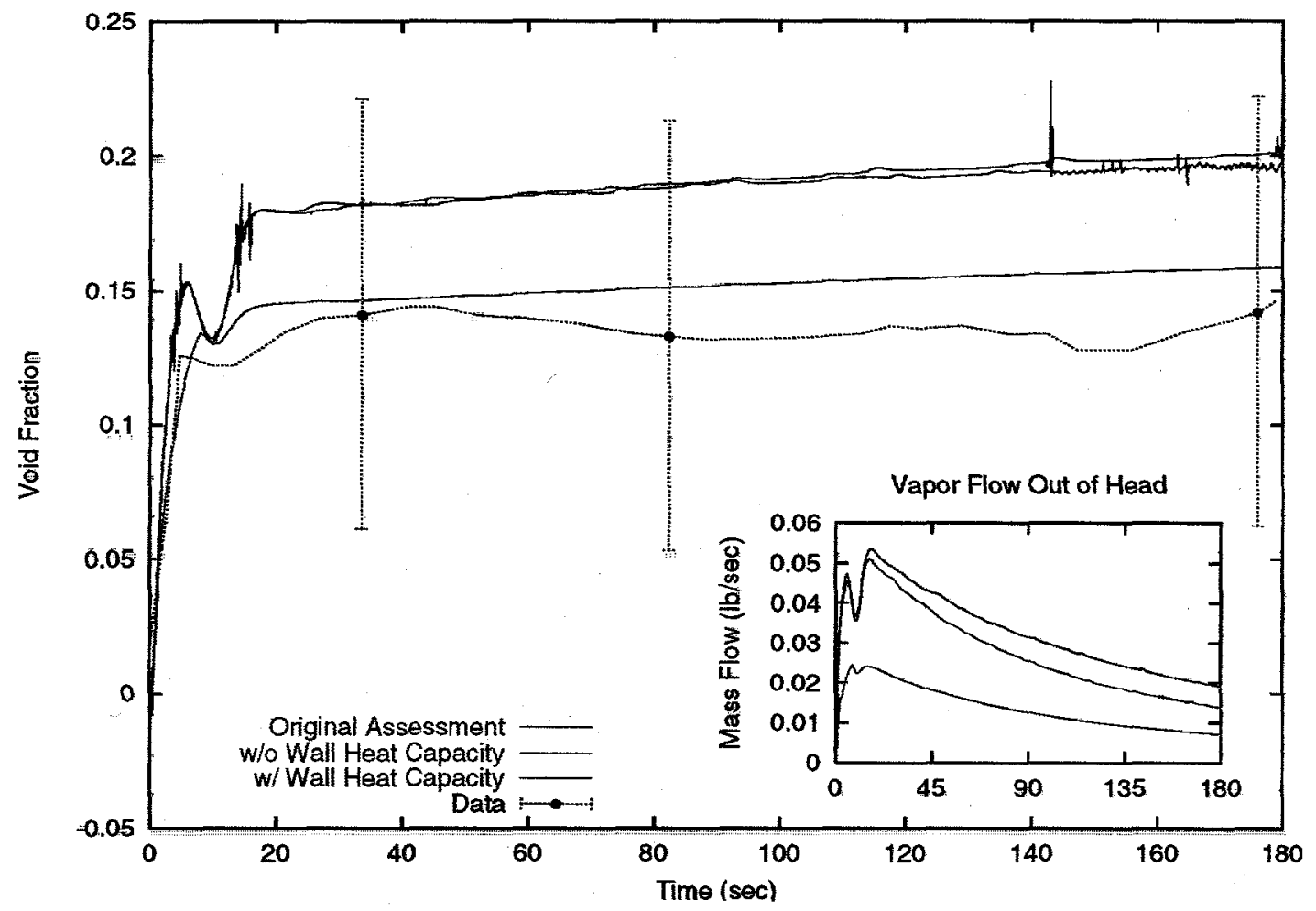

Figure 3: Void Fraction Comparison at Level 1 


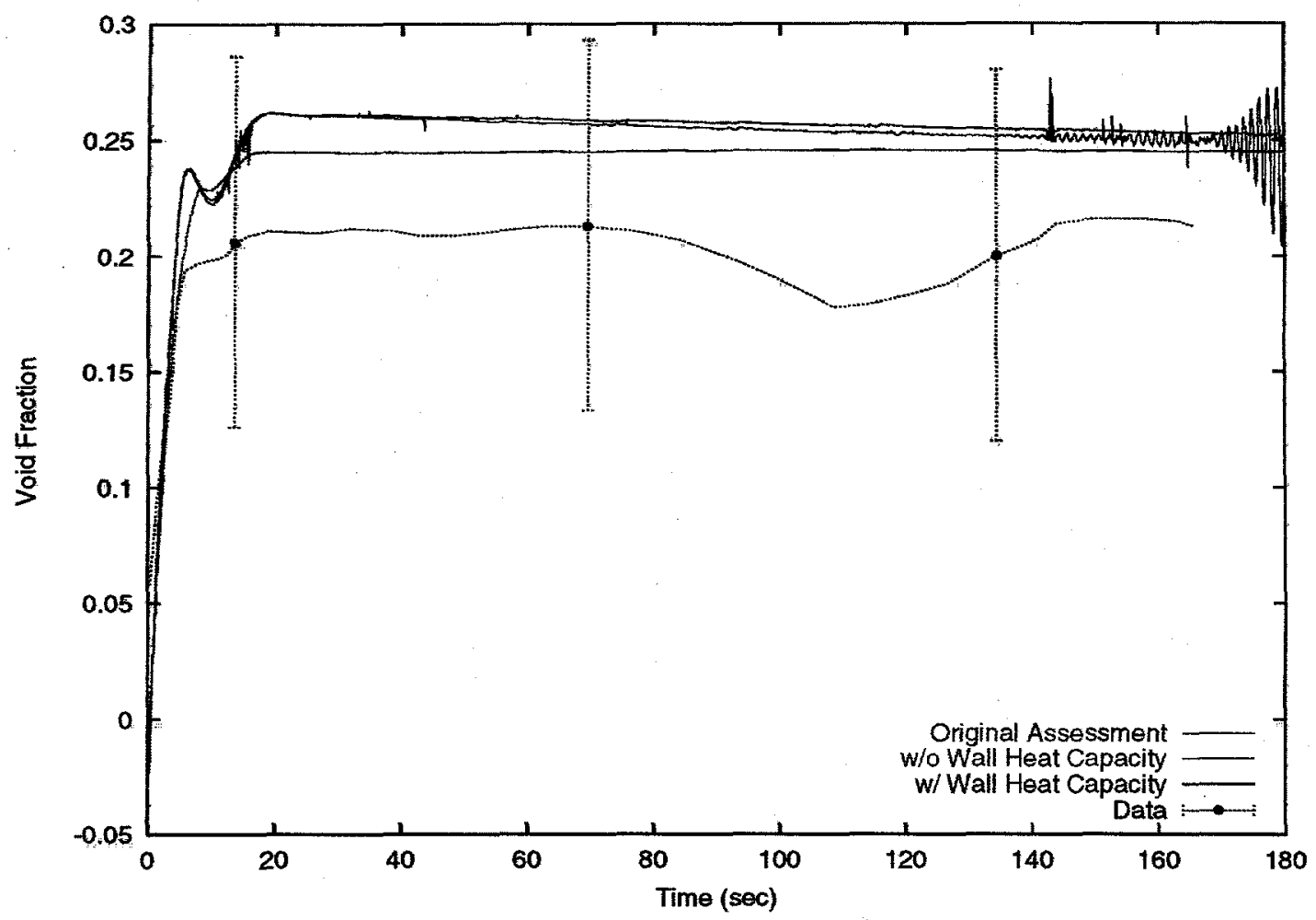

Figure 4: Void Fraction Comparison at Level 2

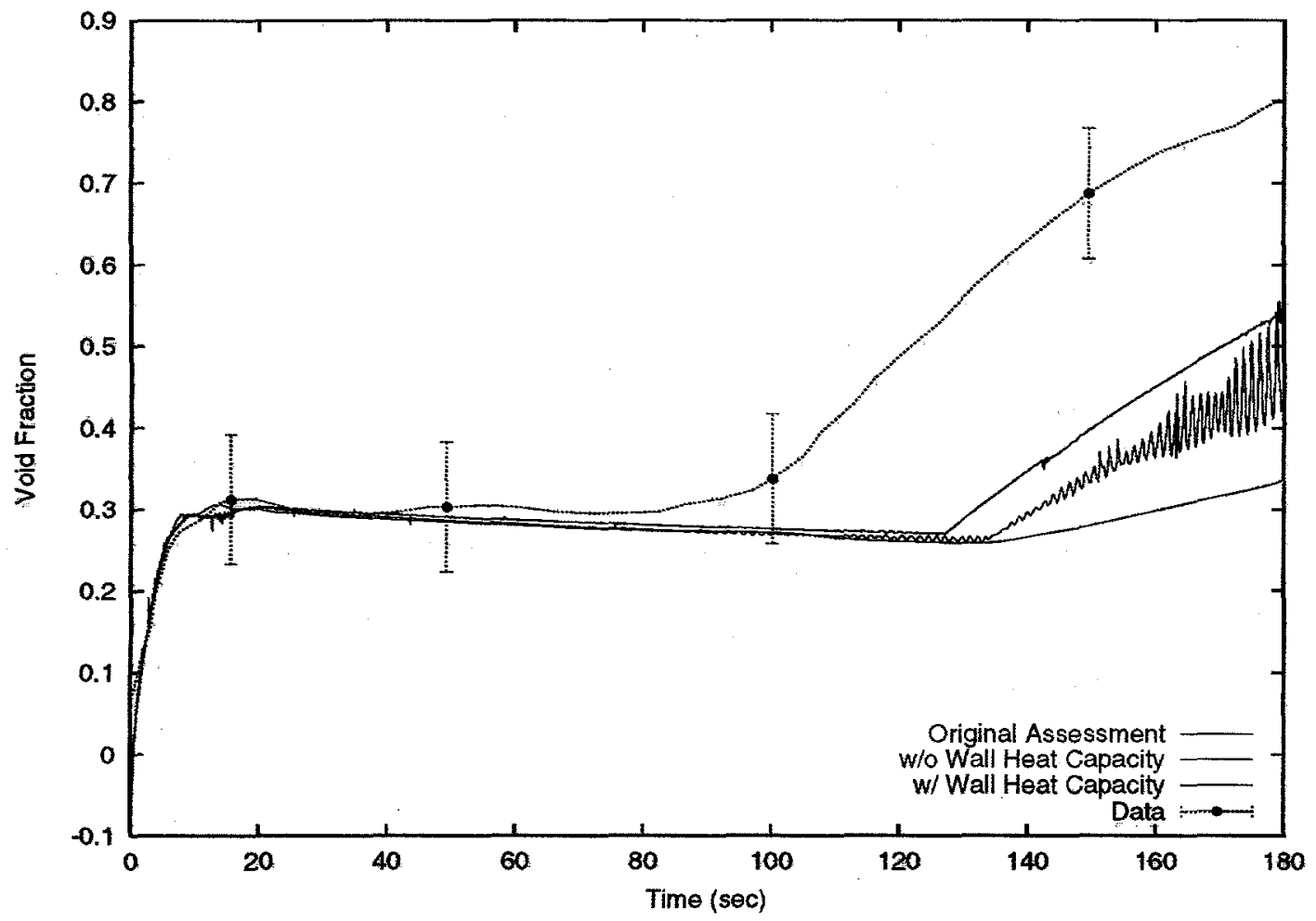

Figure 5: Void Fraction Comparison at Level 4 


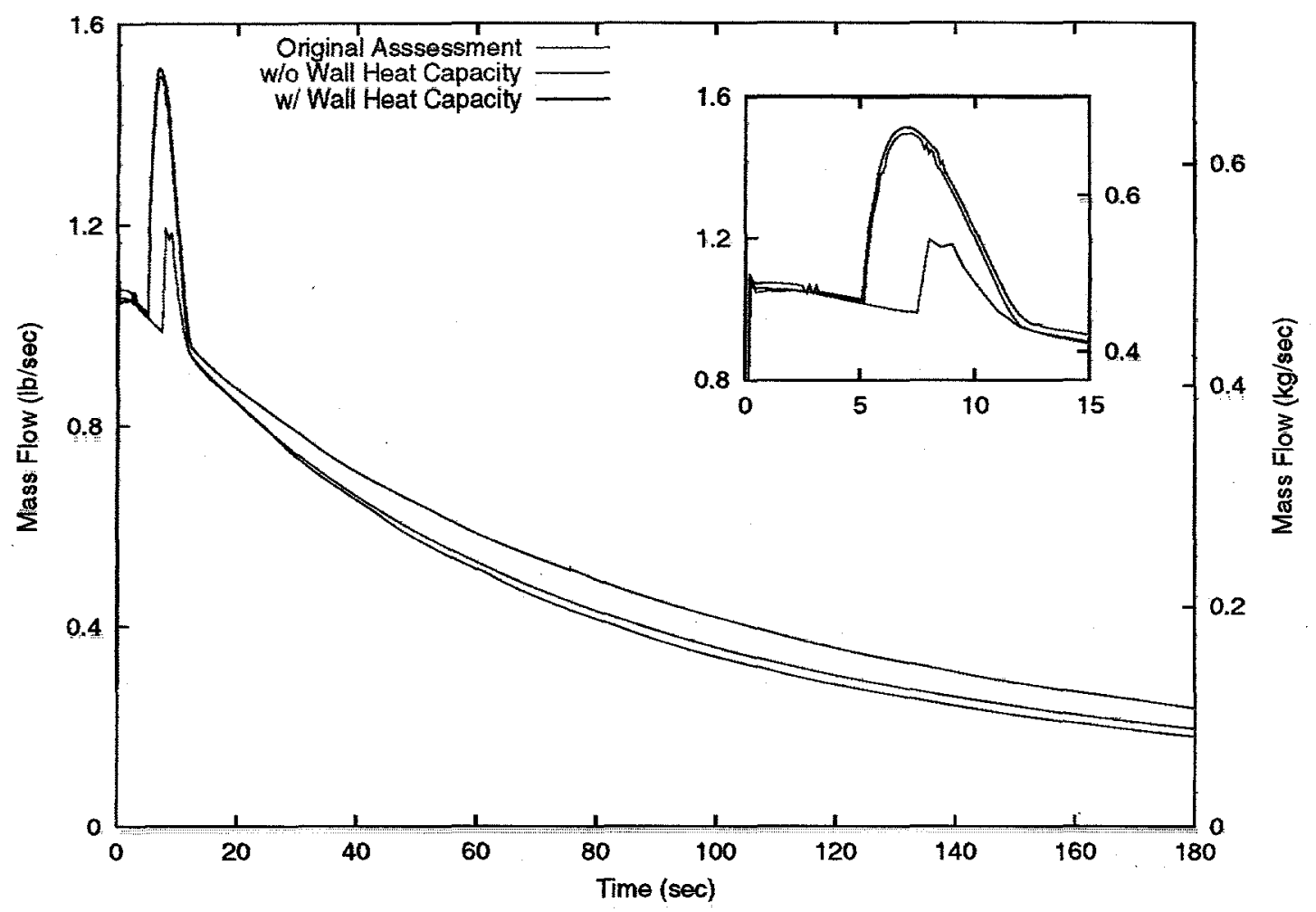

Figure 6: Discharge Flow Comparison for the Different Models

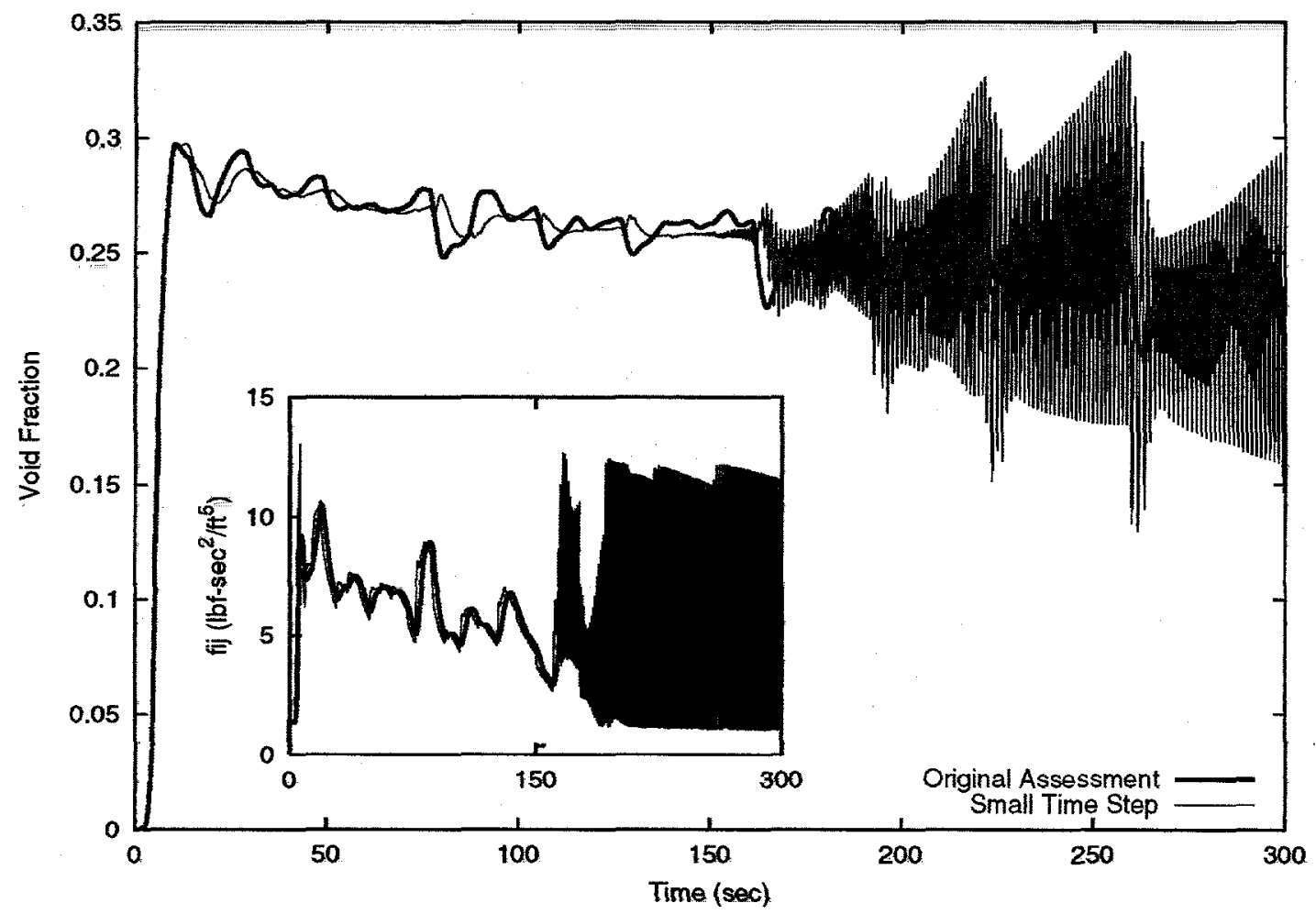

Figure 7: Effect of Timestep Size on the Results of the Original Assessment Problem 


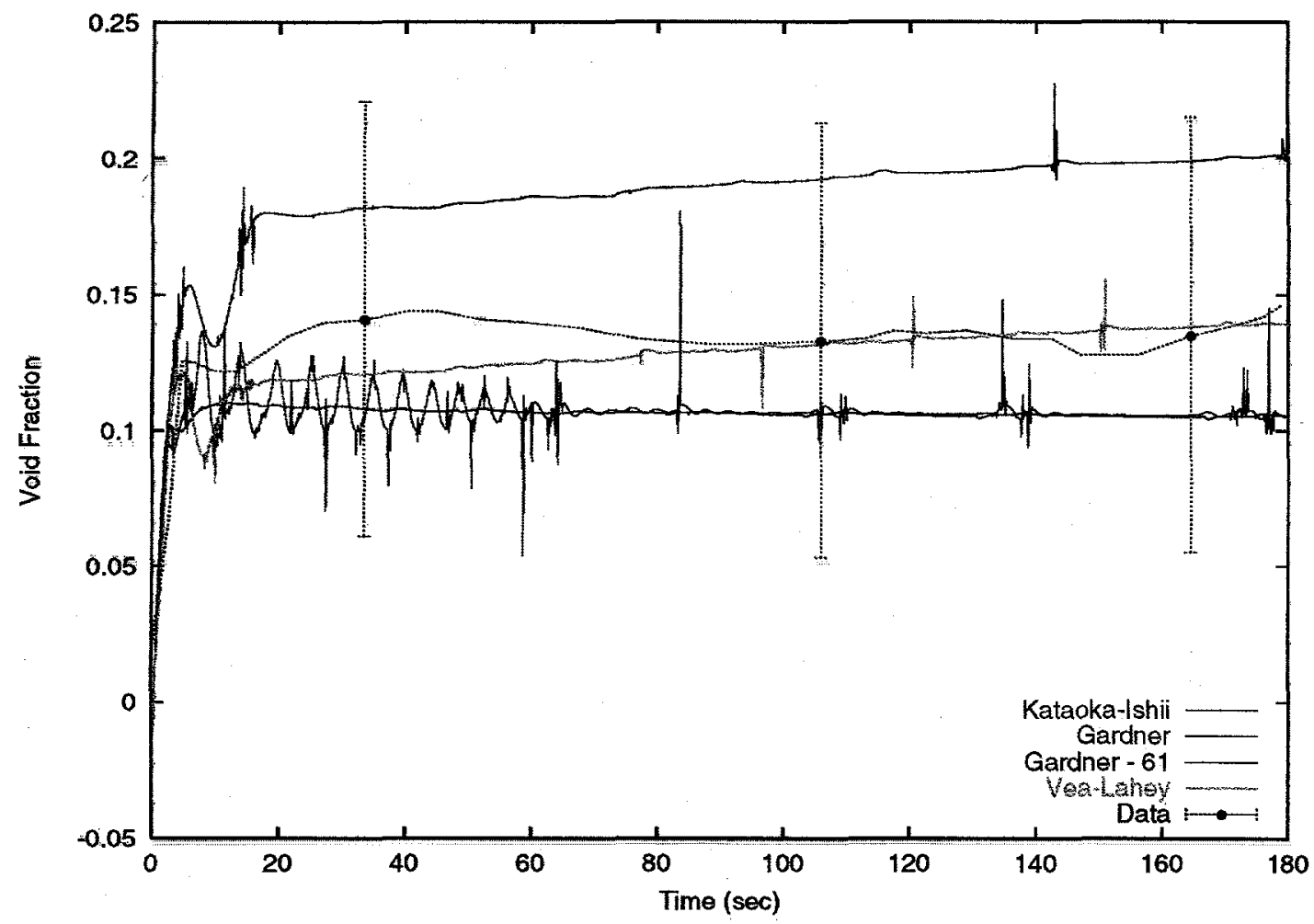

Figure 8: Effeet of Interfacial Drag on Void Fraction in Level 1

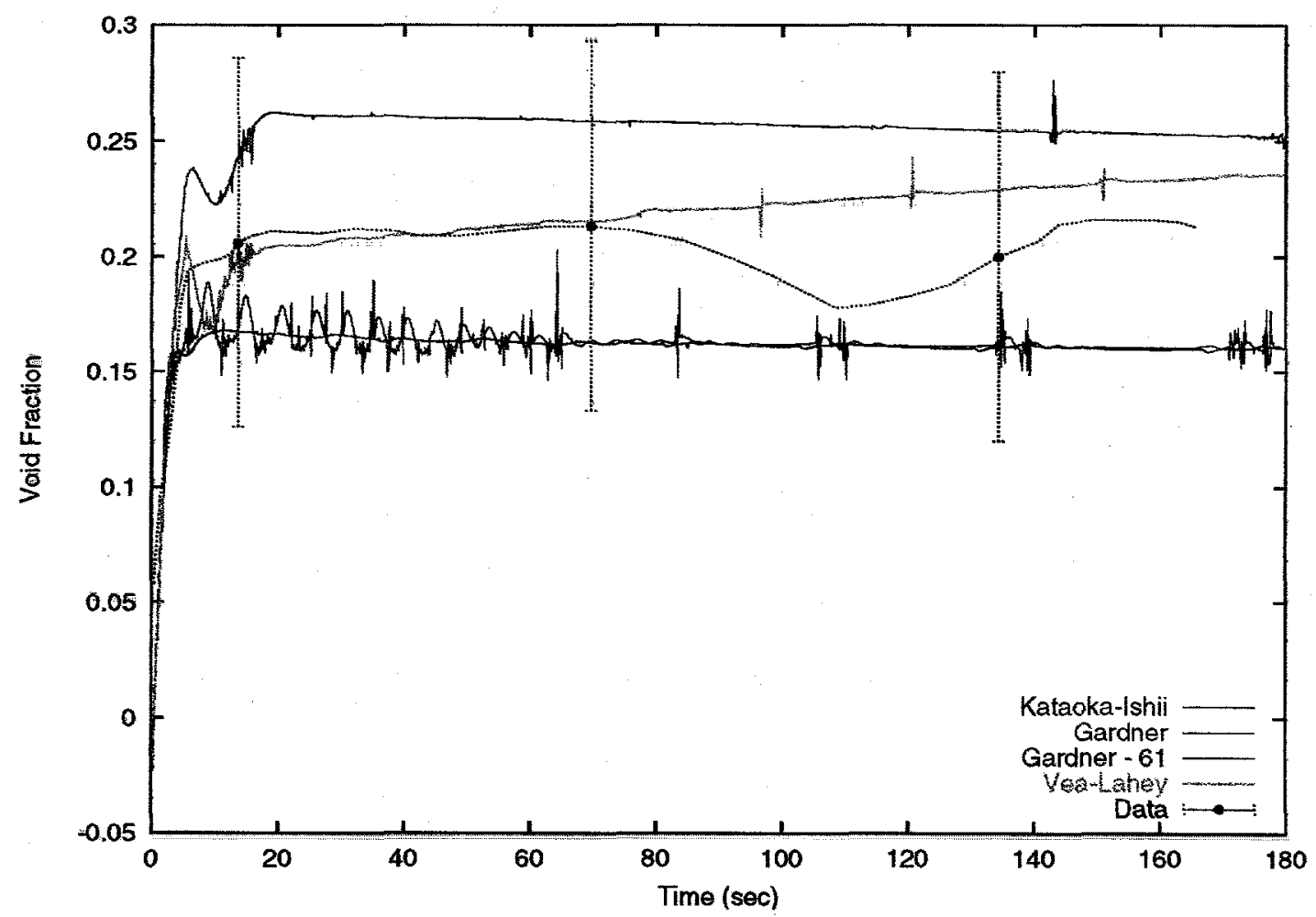

Figure 9: Effect of Interfacial Drag on Void Fraction in Level 2 


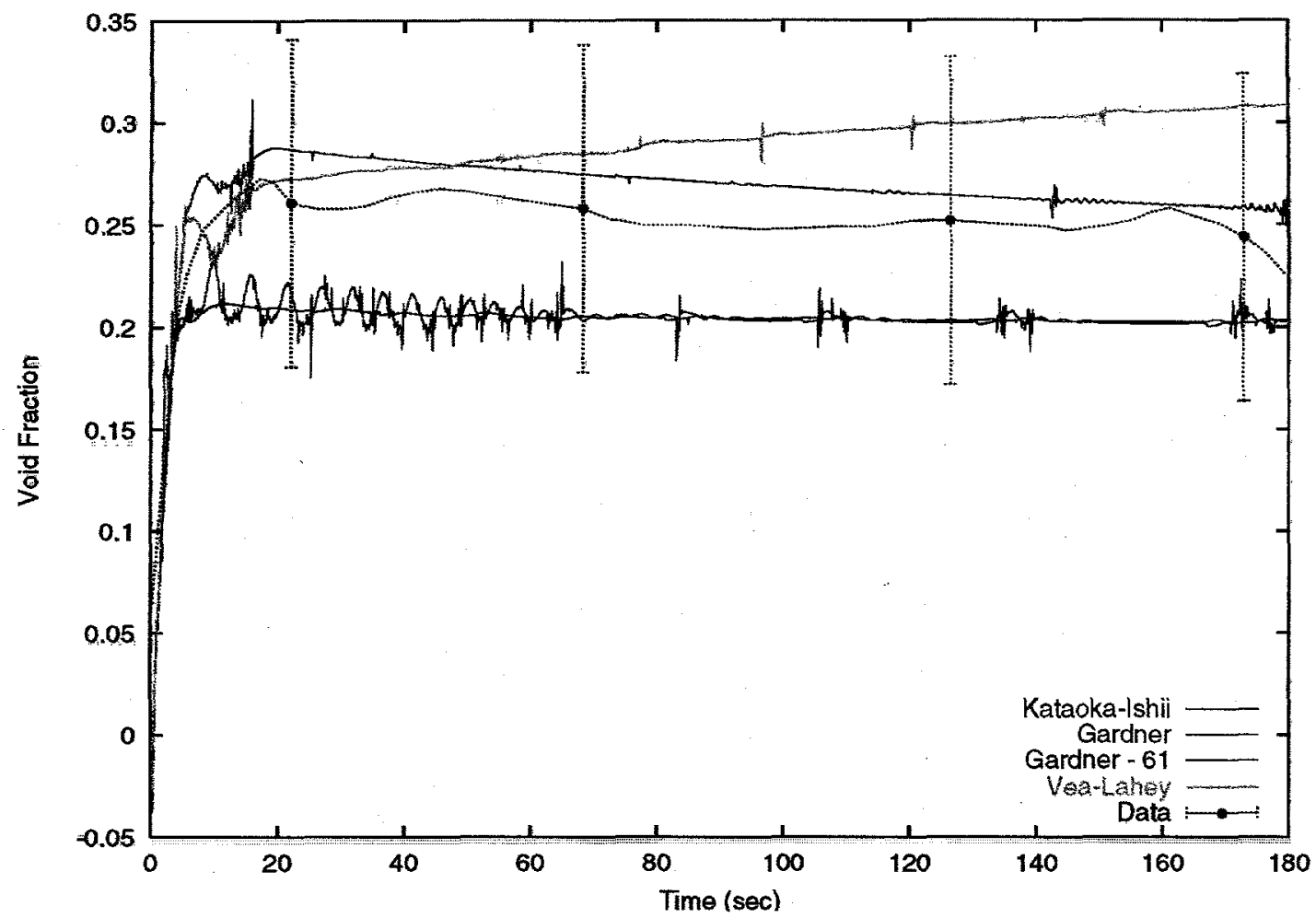

Figure 10: Effect of Interfacial Drag on Void Fraction in Level 3

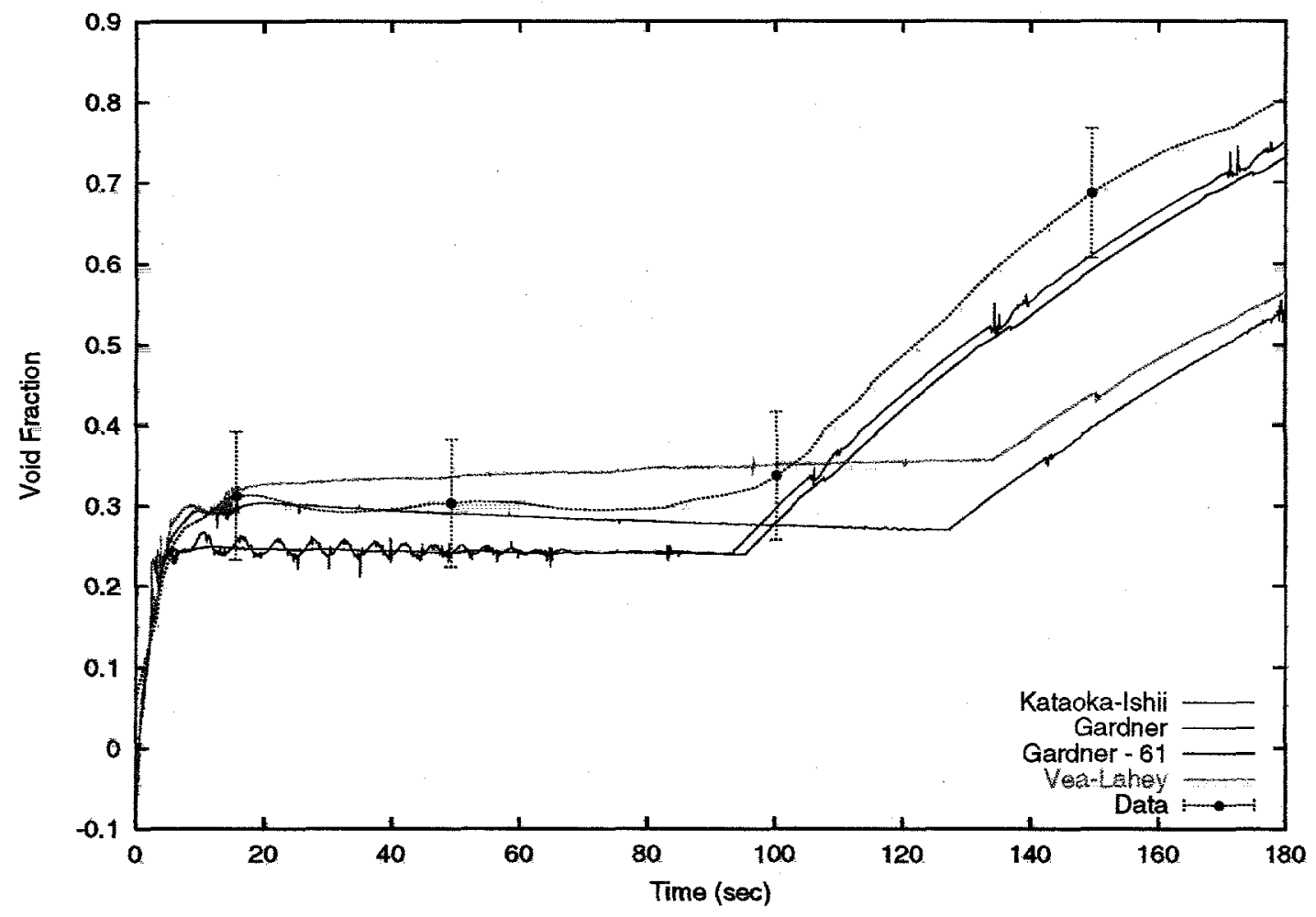

Figure 11: Effect of Interfacial Drag on Void Fraction in Level 4 
September 12-14, 2000

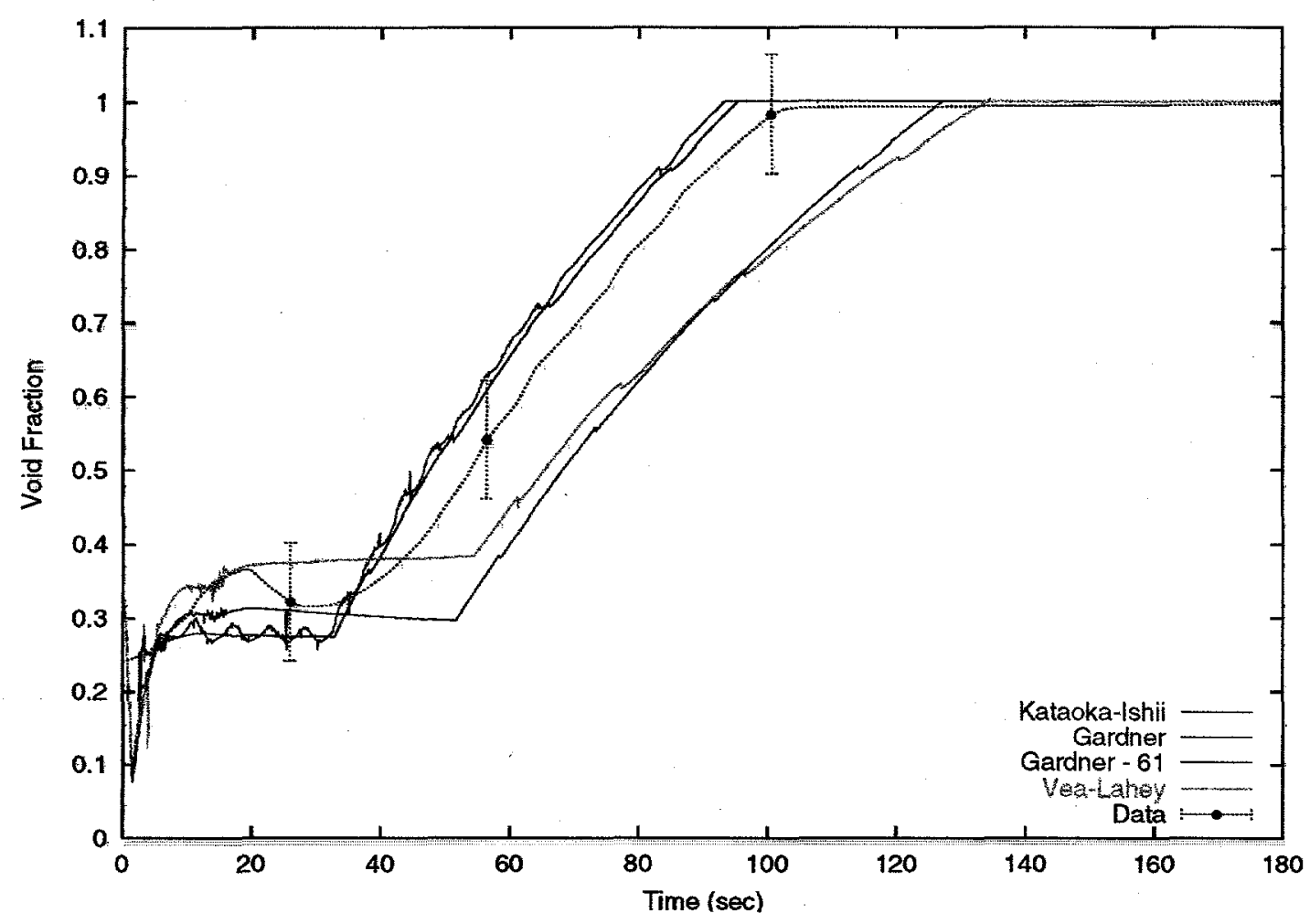

Figure 12: Effect of Interfacial Drag on Void Fraction in Level 5

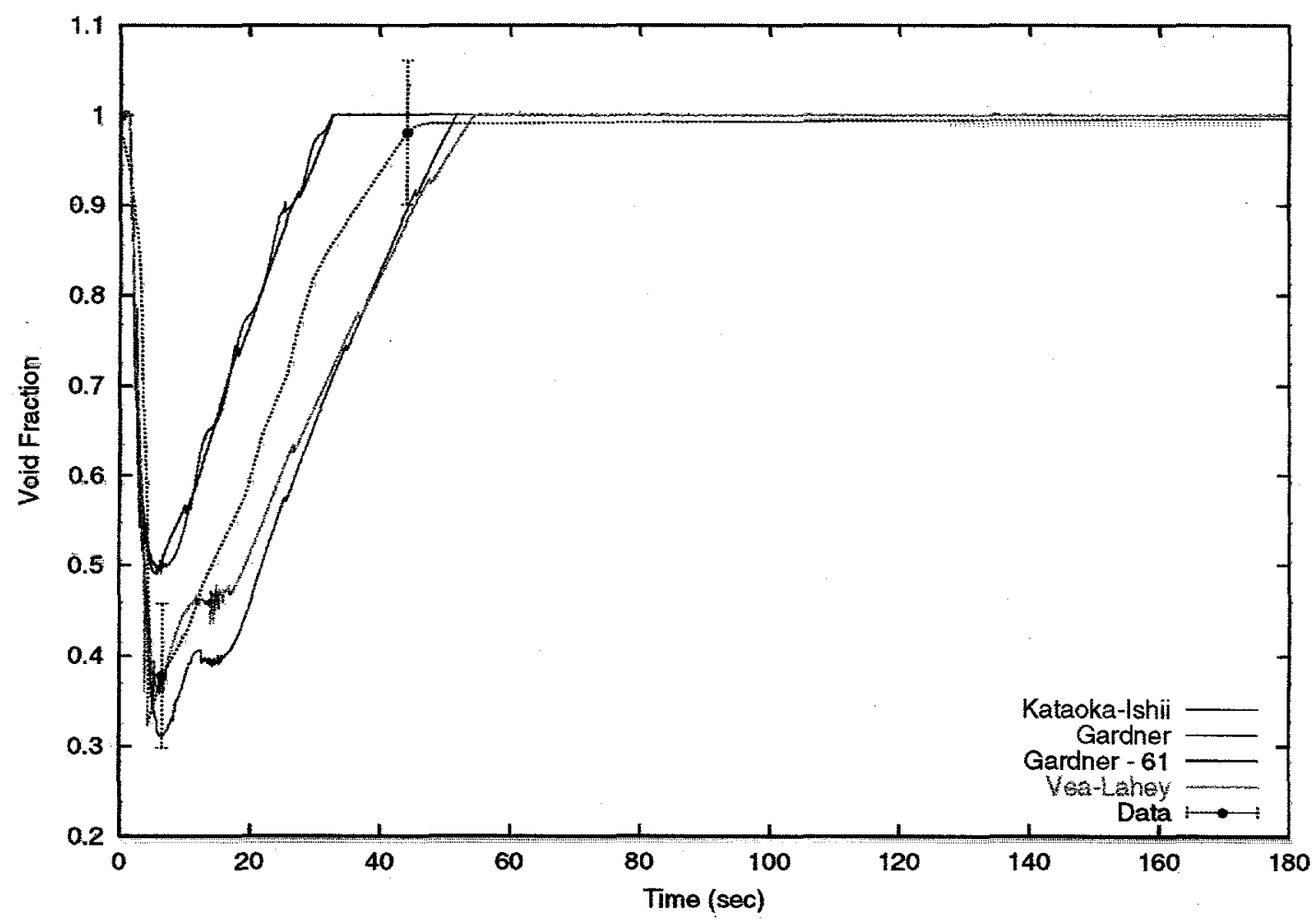

Figure 13: Effect of Interfacial Drag on Void Fraction in Level 6 


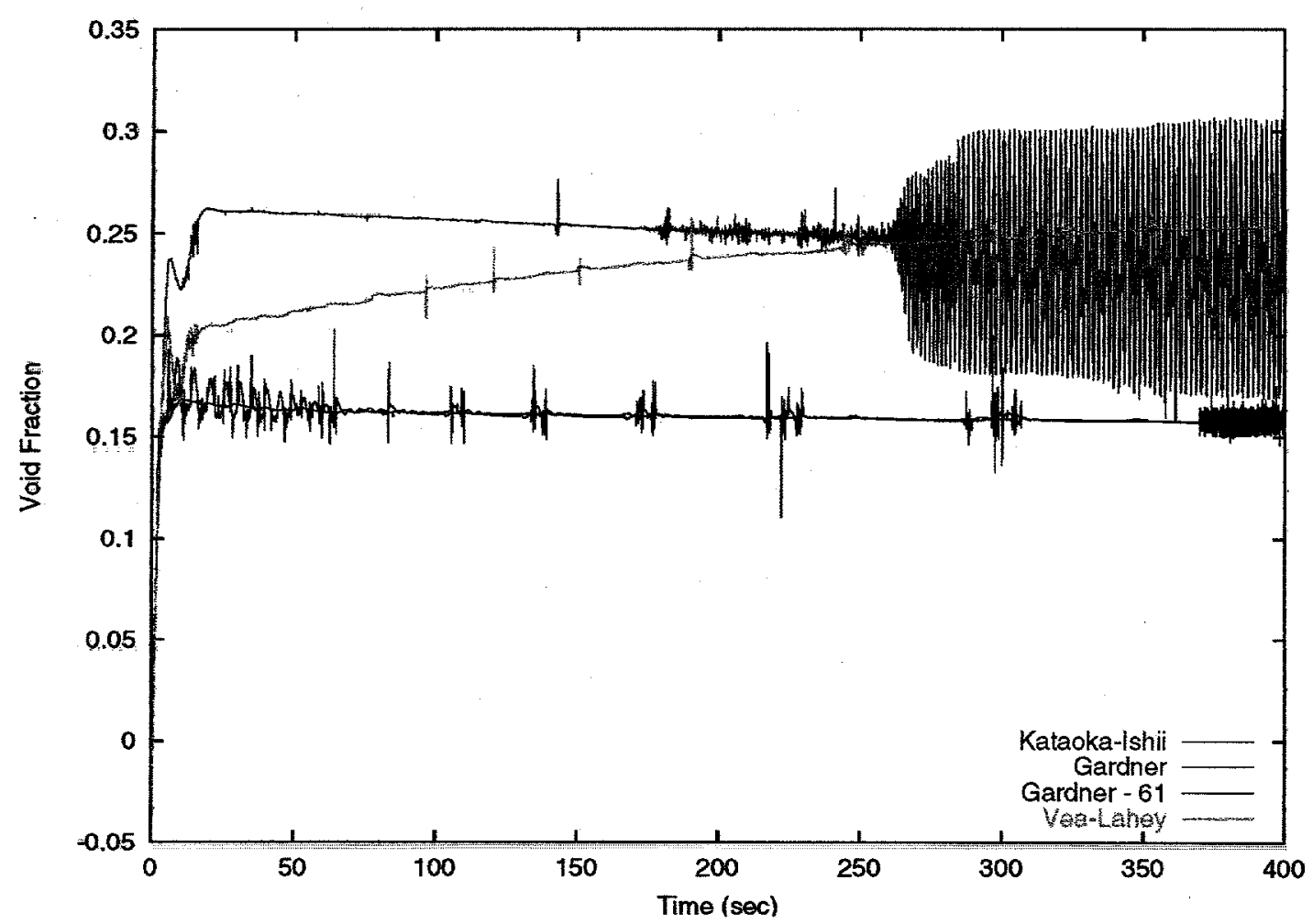

Figure 14: Long Term Void Predictions for Level 2

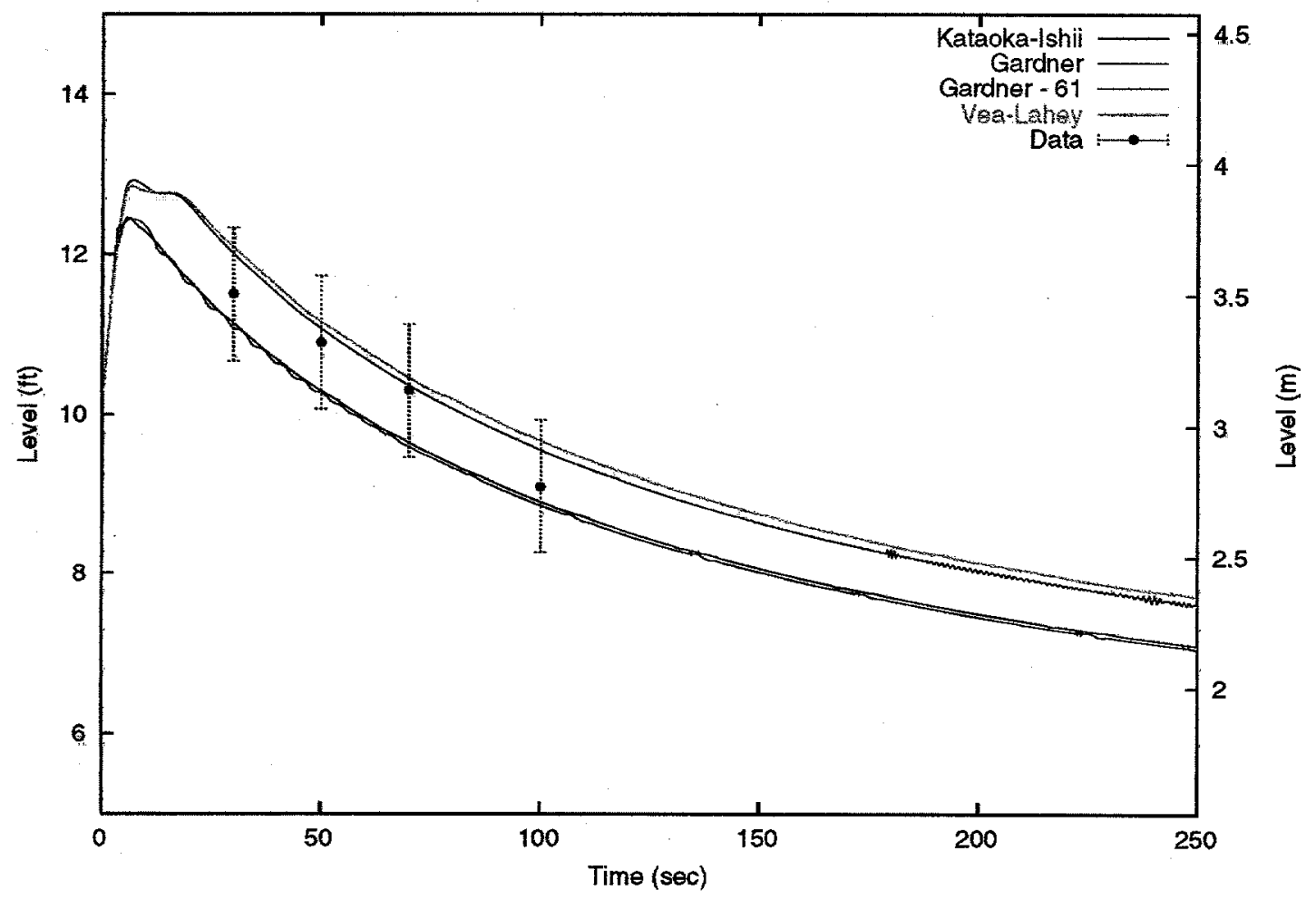

Figure 15: Two-Phase Level Comparison for the Different Interfacial Drag Correlations 
September 12-14, 2000

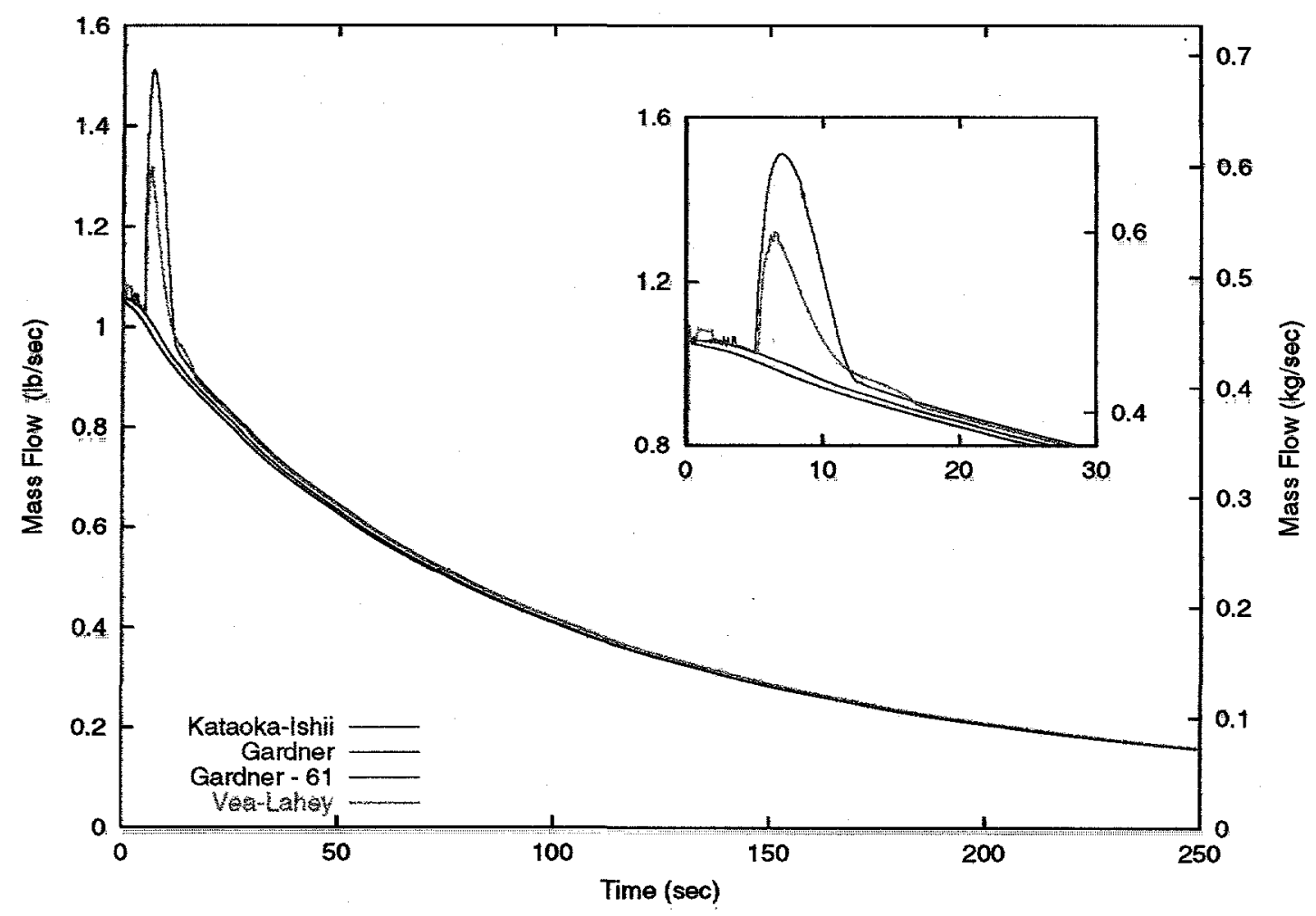

Figure 16: Effect of Interfacial Drag on Mass Flow at the Orifice

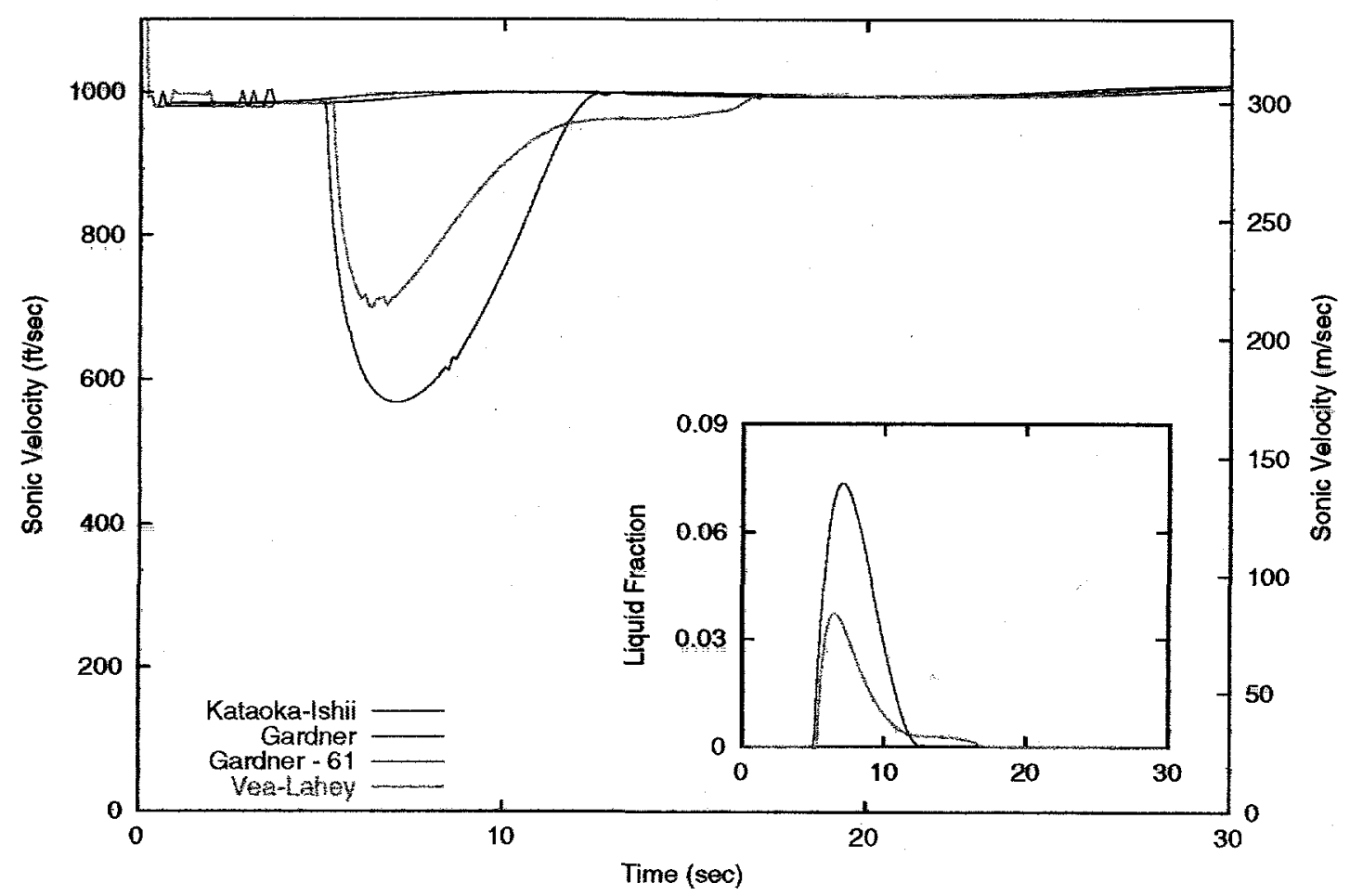

Figure 17: Effect of Liquid Carryover on Sonic Velocity for the Different Drag Correlations 